\title{
Reflexões acerca do uso das Tecnologias Digitais da Informação e Comunicação na formação inicial docente de uma turma de licenciatura em EaD
}

Reflections on the use of Digital Technologies of Information and Communication in the initial teacher training of a class of undergraduate degree in Distance Education

\author{
M. M. S. Alves*; A. A. S. S. Ferrete; W. L. Santos \\ Programa de Pós-Graduação em Educação (PPGED), Universidade Federal de Sergipe (UFS), 49100-000, São \\ Cristóvão-SE, Brasil
}

*messyarts@gmail.com

(Recebido em 10 de agosto de 2020; aceito em 11 de janeiro de 2021)

\begin{abstract}
O objetivo central deste artigo consistiu em analisar o uso das Tecnologias Digitais da Informação e Comunicação (TDIC), enquanto recursos didático-pedagógicos no processo de formação inicial docente em uma turma do Curso de Licenciatura em Ciências Biológicas, modalidade Educação à Distância $(\mathrm{EaD})$, da Universidade Federal de Sergipe (UFS). Buscamos também identificar aspectos da cultura digital dos licenciandos e investigar suas percepções acerca do uso das tecnologias no tocante a atividade docente. Tratase de uma pesquisa de abordagem quali-quantitativa e com viés descritivo, tendo como público-alvo a participação de 22 (vinte e dois) acadêmicos, em sua maioria na fase de conclusão do curso. No que refere aos principais resultados, embora a maioria dos participantes tenha demonstrado possuir níveis satisfatórios e avançados de conhecimentos e habilidades acerca da utilização das TDIC em seu cotidiano, assim como uma concordância unânime de que essas tecnologias, desde que utilizadas adequadamente, contribuem de maneira significativa para a aprendizagem dos educandos, constatou-se também a prevalência de algumas limitações que comprometem a ênfase de abordagens didático-pedagógicas voltadas a implementação das tecnologias digitais, em que $27 \%$ dos participantes relataram ausência dessas abordagens tecnológicas durante sua formação mediante a uma série de fatores relacionados desde a carência de interesse e de capacitação dos professores e tutores, até mesmo a ausência de recursos e desmotivação dos próprios acadêmicos.
\end{abstract}

Palavras-chave: cultura digital, formação docente, letramento digital

The main objective of this article was to analyze the use of Digital Technologies of Information and Communication (DTIC), as didactic-pedagogical resources, in the process of initial teacher training in a class of the Degree in Biological Sciences, Distance Education modality (Distance Education), from the Federal University of Sergipe (FUS). We also seek to identify aspects of the graduates' digital culture and investigate their perceptions about the use of technologies with regard to teaching activity. It is a qualitative and quantitative research with a descriptive bias, having as target audience the participation of 22 (twenty-two) academics, most of them at the conclusion of the course. Regarding the main results, although the majority of the participants demonstrated to have satisfactory and advanced levels of knowledge and skills about the use of DTIC in their daily lives, as well as unanimous agreement that these technologies, provided they are used properly, contribute significantly for the students' learning, it was also found in this study the prevalence of some limitations that compromise the emphasis of didactic-pedagogical approaches aimed at the implementation of digital technologies, with $27 \%$ of the participants reporting the absence of these technological approaches during their training due to a series of factors related from the lack of interest and training of teachers and tutors, to the lack of resources and demotivation of the academics themselves.

Keywords: digital culture, teacher training, digital literacy

\section{INTRODUÇÃO}

As tecnologias fazem parte do processo de evolução social da humanidade e se traduz desde os artefatos pré-históricos, como a descoberta do fogo ou a invenção da roda e demais ferramentas manuais utilizadas pelo homem primitivo, interagindo com os costumes, culturas e fatores existentes nas relações humanas até os recursos mais modernos atuais, como os dispositivos móveis 
digitais [1,2], nesse sentindo, faz-se necessário entender o significado do termo tecnologia e suas representações, que por sua vez, estão em constante evolução.

Ao longo dos anos surgiram importantes descobertas que deram origem às mais variadas tecnologias, cada uma no seu tempo, e de maneira geral, objetivaram atender as demandas sociais e capitalistas das diferentes épocas. Recentemente, o emprego dos recursos tecnológicos transmite a ideia de conforto, praticidade e facilidade, mas não podemos negar que tais inovações acontecem de maneira rápida e que de certa forma, condicionam as pessoas a viverem em constante aperfeiçoamento e aquisição de habilidades para manuseá-las, pois muitos indivíduos podem acabar se tornando cada vez mais dependentes desses recursos digitais [3].

Nessa perspectiva, graças a expansão das Tecnologias Digitais da Informação e Comunicação (TDIC) na primeira década do século XXI, juntamente com o surgimento das tecnologias de conexão sem fio, por meio dos serviços de telefonia móvel e conexão wireless (3G, $4 \mathrm{G}, \mathrm{Wi}$-Fi), um número elevado de pessoas passou a ter acesso a uma maior variedade de dispositivos móveis, principalmente aos telefones celulares com tecnologias avançadas equivalentes aos computadores - os populares smartphones -, e tiveram suas vidas significativamente modificadas ou adaptadas [4], sobretudo no que se refere aos modos de agir, aprender, pensar e interagir na sociedade em rede $[1,5,6]$.

As discussões acerca do uso educacional das tecnologias ganharam destaque na atualidade, visto que ao contrário do século passado, a maioria dos alunos tem acesso a diferentes dispositivos móveis, e inclusive os levam para a sala de aula, o que reforça a necessidade de incluir ou aprimorar esse debate na formação docente, tanto nos cursos de formação inicial quanto continuada, com foco nas práticas didático-pedagógicas para que os professores possam se apropriar dessas tecnologias no âmbito educacional e em diversos outros contextos sociais [5].

Nessa perspectiva, torna-se evidente que as mudanças provocadas pela incorporação das TDIC no processo de ensino e aprendizagem, incluindo a contribuição proporcionada pela internet com seus recursos dinâmicos e interativos, têm exigido e possibilitado novas configurações na educação que, por sua vez, vão além da mera modernização das práticas educativas, e comportam formas de apropriação crítica e contextualizada desses dispositivos na formação docente, ao mesmo tempo que despertam novas perspectivas nas relações pedagógicas entre professores e alunos [7,8].

Ao relacionar essa discussão com cenário atual, considerando os desafios impostos à humanidade para o enfrentamento do novo coronavírus (SARS-CoV-2), causador da pandemia da COVID-19 - que além de afetar o sistema de saúde em escala global, tem prejudicado também vários outros setores como a educação, economia e segurança pública, por exemplo -, nunca os serviços de home working (teletrabalho, trabalho remoto ou trabalho à distância) e de distance learning (ensino a distância) tinham sido tão requisitados antes [9], visto que a principal medida a ser adotada a fim de diminuir a disseminação desse vírus, é restringir o contato físico entre as pessoas, principalmente por meio do distanciamento social, na qual a integração das tecnologias ao cotidiano tem se tornado estratégia importante para garantir a manutenção e acesso aos serviços essenciais, e no que se refere ao âmbito escolar, promove a construção de novas possibilidades no processo de ensino e aprendizagem.

Com efeito, Gewehr (2016) [10] alerta sobre a necessidade de superar a substancial, porém equivocada, ideia disseminada ao longo dos anos de que a tecnologia se restringe aos diferentes recursos e equipamentos eletrônicos ou digitais de última geração, na qual concordamos com esse autor sobre a importância de compreender como a tecnologia está empregada nas ações do cotidiano, principalmente nos dias atuais devido ao enfretamento da COVID-19, que em caráter emergencial, fez flexibilizar e incorporar seu uso em diferentes relações sociais. No entanto, uma inquietação merece ser considerada nesse contexto: será que os educadores vivenciaram em sua formação inicial, abordagens didático-metodológicas que contemplassem o uso das tecnologias como estratégia facilitadora da atividade docente?

Apesar da realização de atividades à distância já ser autorizada na Educação Básica há mais de duas décadas, pela Lei de Diretrizes e Bases da Educação Nacional (LDBEN), Lei no 9.394 de 1996, como complementação da aprendizagem ou em situações emergenciais, bem como recentemente, a Base Nacional Comum Curricular (BNCC) referente ao Ensino Médio, também tenha demonstrado preocupação com os impactos e transformações sociais ocasionadas pela evolução tecnológica, ao enfatizar conhecimentos, habilidades, valores e atitudes voltadas as 
diferentes dimensões das tecnologias digitais, como o pensamento computacional, mundo digital e cultura digital [11, 12], parece que só agora, com pandemia da COVID-19, é que o tradicional modelo de ensino do nosso país está sendo rompido, ou pelo menos, repensado e adaptado a essa realidade emergente. Assim, é notório os esforços das instituições de ensino e do próprio Ministério da Educação (MEC) em promover o uso das TDIC, juntamente com as metodologias ativas e demais recursos (redes sociais, WhatsApp, aplicativos, plataformas educacionais, etc.) vinculados a Educação à Distância $(\mathrm{EaD})$, como estratégias para garantir a continuidade da educação em tempos de pandemia, inclusive no Ensino Superior, que em caráter excepcional, por meio da Portaria $n^{\circ} 343$ de 17 de março deste ano, o MEC autorizou que instituições públicas e privadas de educação superior substituíssem disciplinas presenciais por aulas on-line nos cursos em andamento [13].

Nessa perspectiva, o ritmo acelerado em que as mudanças e inovações tecnológicas ocorrem tem despertado importantes impactos culturais, científicos e educacionais, as quais exigem novos modelos de análise e de adaptação a essa realidade nos diferentes contextos sociais, inclusive no âmbito escolar $[10,13]$. Por esse motivo, não podemos ignorar as possibilidades e os desafios do uso das tecnologias no processo de ensino e de aprendizagem, sobretudo das tecnologias móveis, que mesmo diante de suas potencialidades pedagógicas, se não forem devidamente pensadas e adequadas às diferentes realidades sociodemográficas e econômicas, podem ampliar ainda mais o risco de desigualdades de acesso à educação em diversas regiões do país [14].

Corroborando com essa discussão, Marinho et al. (2015) [4] apontam importantes relações entre redes e mídias sociais, na qual, para esses autores, as redes sociais "podem ser formadas por pessoas que compartilham objetivos comuns e não precisam estar limitadas a uma estrutura hierárquica" ( $\mathrm{p}$. 836), podendo estar presentes nos mais variados contextos sociais; enquanto que as mídias sociais, por sua vez, possuem relação com o tipo de tecnologia utilizado para que os usuários das redes possam se comunicar, ou seja, por ser algo mais amplo, as mídias sociais possibilitam o surgimento de determinada rede social. Desse modo, ao relacionar essa discussão com as consequências trazidas pelo enfrentamento do novo coronavírus, sobretudo na esfera da educação em meio da necessidade de distanciamento social, percebemos o quanto o avanço da educação digital e on-line contribui para que as atividades de ensino e a aprendizagem ultrapassem as barreiras físicas da escola e cheguem ao alcance de todos, até mesmo por meio de interfaces disponíveis na internet consideradas informais, como apontam Santos et al. (2020) [15], na qual o próprio Facebook, desde que em consonância com objetivos pedagógicos, "pode contribuir significativamente para o andamento do processo de ensino-aprendizagem, considerando as diferentes ferramentas disponíveis na web e suas funcionalidades" (p. 4), principalmente no compartilhamento de ideias, arquivos de mídia, links, criação de comunidades, chats, videoconferências, dentre outras possibilidades.

Nessa conjuntura, a associação desses recursos com as mídias digitais em geral, favorece as relações de comunicação entre rede e mídia social, expressas na maioria das vezes através de textos, hipertextos, sons, imagens, vídeos, gráficos, etc., que permitem uma interface de novas formas de expressão do indivíduo com o mundo digital $[3,16]$. Buscando compreender as relações existentes entre o ser humano, tecnologia e cultura, Lévy (1999) [1] e Lemos (2015) [6] apresentam importantes contribuições acerca da cultura digital, a qual esses autores atribuem o termo de cibercultura, caracterizada por uma nova relação entre tecnologias e sociabilidade numa sociedade conectada e colaborativa, ancorada nos múltiplos recursos e possibilidades da internet.

Vale a pena lembrar que embora a origem da internet tenha ocorrência histórica na década de 1960 com a Guerra Fria, sua expansão ocorreu de forma acelerada juntamente com o desenvolvimento das tecnologias interativas na última década do século passado. Esse fenômeno tecnológico, cuja finalidade inicial voltava-se a fins militares, passou por várias revoluções e, atualmente, como ressaltado, está presente no convívio social das pessoas, repercutindo em transformações socioeconômicas e socioculturais, pois segundo Lemos (2015) [6], a "internet encarna a presença da humanidade e a ela própria, já que todas as culturas, todas as disciplinas, todas as paixões aí se entrelaçam" (p. 13).

Nesse sentindo, a Grande Rede Mundial (Word Wide Web) ou, simplesmente, Web, corresponde a um ambiente social de interações por meio de hipertextos e de multimídias capazes de possibilitar aos usuários uma maior interação e conectividade com emissores, conforme suas necessidades e 
interesses [17]. Dessa forma, o conceito de Web se entrelaça com a própria evolução da cibercultura e das TDIC, tendo em vista suas configurações e possibilidades de integração na grande rede mundial, a Web 2.0, que por sua vez, está passando por novas transformações, podendo até mesmo a se pensar numa projetação para uma nova Web, denominada previamente de "Web 3.0", tendo como diferencial a cooperação existente na relação entre humanos e computadores $[10,18]$.

É importante considerar que a cultura contemporânea contempla uma relação simbiótica entre o homem, a natureza e a sociedade integrada às tecnologias digitais, à qual Lemos (2015) [6], define como uma exemplificação de cibercultura, ou seja, uma nova forma de cultura que está presente em todas as atividades da vida diária. Nesse contexto, as mídias e redes sociais, propagadas pela cibercultura, adentram nos mais variados ambientes, se mostrando eficazes no atual cenário de distanciamento social decorrente da crise de saúde pública que a humanidade está vivenciando, e o espaço escolar não poderia ficar de fora de seu alcance, por isso, não podemos ignorar as possibilidades e os desafios do uso das tecnologias no processo de ensino e de aprendizagem, sobretudo das tecnologias móveis, tendo em vista suas potencialidades pedagógicas.

No entanto, a presença das TDIC, de maneira geral, ainda se encontra em progressão na educação brasileira, pois esses dispositivos passaram a ser introduzidos de maneira tímida nos ambientes escolares por meio da implantação da informática e de demais elementos relacionados a área de tecnologias na educação [19]. Por esse e outros motivos, é notório a existência de alguns desafios relacionados à adequação do ambiente escolar para a integração das TDIC em sua prática educativa, tendo em vista que a simples presença dos dispositivos digitais em sala de aula, até então, não era suficiente para promover a cultura digital nas instituições de ensino. Dentre as principais limitações, destacam-se a necessidade de uma estrutura física adequada, capaz de proporcionar acesso de qualidade à rede e, principalmente, uma reformulação no currículo escolar com ênfase na formação pedagógica inicial e continuada de professores e gestores, para garantir assim, qualidade e dinamismo das práticas pedagógicas por meio da tecnologia $[4,19]$.

Atualmente, as TDIC consideradas mais populares entre os diferentes públicos são os smartphones, tablets, notebooks, leitores de livro digital (e-reader), aparelhos portáteis de áudio e vídeo (MP3, MP4), etc. [4]. Inferimos neste estudo que o uso educativo de tais dispositivos pode ampliar as possibilidades e garantir uma educação mais qualificada e inclusiva digitalmente, capaz de estimular o educando quanto à observação e problematização sob uma visão crítica, cooperativa e comprometida com a busca e a difusão do conhecimento.

No que diz respeito às práticas de ensino integradas as tecnologias móveis, Silva e Moraes (2014) [5] ressaltam a importância de promover procedimentos didáticos que privilegiem a construção colaborativa dos conhecimentos mediada pela figura do professor, a fim de possibilitar experiências diversificadas de ensino e aprendizagem aos discentes com a utilização desses dispositivos. Assim, para um melhor aproveitamento do uso das tecnologias em sala de aula, o planejamento prévio e adequado é um fator fundamental para a incorporação de ações e atividades escolares integradas ao uso das tecnologias móveis digitais, podendo inclusive, fazer transposição didática de plataformas informais, como a própria rede social Facebook, para despertar o interesse e engajamento dos discentes nesse processo [7, 15].

Para que as TDIC proporcionem uma construção de saberes por meio de descobertas, aprimoramento e motivação no âmbito educacional faz-se necessário, dentre outros fatores, pensar e agir em rede, para que o professor reconheça a importância desses instrumentos e os incorporem em suas práticas didático-pedagógicas, propagando assim, a cultura digital. Dessa forma, é necessário também rever e refletir sobre as concepções de sociedade, de escola e de sujeito, suas relações com o currículo, aprendizagem e o perfil do professor e do aluno para que a apropriação e efetivação das TDIC aconteçam nas práticas de ensino [14, 19].

Diante do exposto, o presente estudo teve como objetivo principal analisar o uso das TDIC, enquanto recursos didático-pedagógicos, no processo de formação inicial docente em uma turma do Curso de Licenciatura em Ciências Biológicas, modalidade EaD, da Universidade Federal de Sergipe (UFS). Considerando ainda as tendências e a necessidade de adaptação a essa sociedade digital, buscamos também identificar aspectos da cultura digital dos licenciandos participantes e investigar suas percepções acerca do uso das tecnologias no tocante a atividade docente.

Assim, é evidente a necessidade do atual sistema de educação, em acompanhar as transformações sociais as quais, boa parte delas, está relacionada com os avanços tecnológicos, 
sobretudo, com a disseminação do acesso à internet, que implicam numa cultura digital cada vez mais presente no meio educacional.

\section{MATERIAL E MÉTODOS}

Este estudo é uma derivação de outra pesquisa em desenvolvimento, cujo foco envolve o uso de cenários virtuais de aprendizagem com estudantes e professores da Educação Básica, submetida e aprovada pela Comissão de Ética e Pesquisa (CEP) da UFS, conforme o parecer $n^{\circ}$. 3.773.965, a qual nos despertou interesse em ampliar e adaptar essa investigação para o Ensino Superior.

Considerando a combinação de aspectos qualitativos e quantitativos na produção e análise dos dados, a presente pesquisa pode ser classificada como de abordagem mista, ou quali-quantitativa e com caráter descritivo. Convém ressaltar que tanto as técnicas quantitativas quanto as qualitativas possuem potencialidades e limitações, e de maneira geral, costumam ser utilizadas com propósitos distintos, na qual os dados quantitativos podem ser analisados estatisticamente para revelar informações úteis, de maneira rápidas e confiáveis, na medida em que as técnicas qualitativas oferecem diferentes perspectivas acerca do tema e dos aspectos subjetivos dos fenômenos estudados. Por essas razões, é evidente a vantagem de promover a integração dessas abordagens para garantir maior consistência dos resultados da pesquisa e melhores possibilidades analíticas $[20,21]$.

É possível a inclusão de abordagens qualitativas e quantitativas em um mesmo estudo, sem que haja, necessariamente, classificação de inferioridade ou superioridade entre essas categorias, nem tampouco definir uma delas como a verdadeira, tendo em vista sua utilização em diferentes etapas do processo da pesquisa [20, 21]. Dessa forma, optamos pela integração dessas abordagens para analisar os fenômenos investigados, bem como interpretar e atribuir significado para as relações subjetivas existentes entre os sujeitos envolvidos.

Os atores sociais participantes deste estudo ficaram dividido em dois grupos, sendo o primeiro composto por 03 professores/pesquisadores, com notável experiência e importantes contribuições em pesquisas relacionadas com a formação docente e o uso das TDIC na educação, que colaboraram especificamente para o processo de validação qualitativa de um questionário, enquanto que o segundo grupo correspondeu a uma amostra de 22 (vinte e dois) acadêmicos do Curso de Licenciatura em Ciência Biológica da UFS, matriculados na modalidade $\mathrm{EaD}$, sendo este último, o público-alvo da pesquisa.

Convém lembrar que a oferta de cursos de graduação na modalidade EaD na UFS é coordenada pelo Centro de Educação Superior à Distância (CESAD) desde ano de 2006, e vinculada ao Sistema Universidade Aberta do Brasil (UAB) [22]. Nesse sentido, os licenciandos participantes estavam vinculados a 08 polos de apoio presencial, especificamente, nos municípios de Arauá, Brejo Grande, Estância, Japaratuba, Lagarto, Poço Verde, Propriá e São Domingos, contemplando assim, diversas realidades sociodemográficas do Estado de Sergipe.

Entre os principais fatores que contribuíram para a realização desta pesquisa com o públicoalvo, destacou-se a atuação voluntária de um dos autores, como Professor Coordenador da disciplina de 'Estágio Supervisionado II: no ensino de Ciências e Biologia', o que possibilitou interação com a turma pelo Ambiente Virtual da Aprendizagem (AVA) e durante os encontros presenciais. Vale a pena lembrar que este estudo atendeu os princípios éticos estabelecidos pelo Conselho Nacional de Saúde, respeitando a Resolução $n^{\circ}$ 510/2016, que trata das pesquisas com seres humanos, na qual os sujeitos foram convidados a participar da pesquisa por livre e espontânea vontade, demonstrada através de um Termo de Consentimento Livre e Esclarecido (TCLE), redigido em forma de carta convite, além do respeito a confidencialidade e a privacidade dos participantes, garantindo assim, o anonimato e a liberdade de desistirem de prosseguir com a pesquisa a qualquer momento [23].

Para que um questionário e demais instrumentos de avaliação adquiram confiabilidade e representatividade das respostas dos sujeitos envolvidos, é necessário se atentar a alguns processos de validação [24-26]. Nesta pesquisa, a validação qualitativa do questionário contou com a contribuição dos 03 pesquisadores citados e ocorreu em duas etapas para obter um consenso satisfatório acerca dos critérios avaliados e atender os objetivos da pesquisa, como a percepção dos 
acadêmicos acerca do uso das TDIC no âmbito educacional, e como essas abordagens são empregadas em sua formação, bem como identificar aspectos da cultura digital desses sujeitos. $\mathrm{O}$ questionário validado foi desenvolvido através da plataforma de Formulários do Google, ou 'Google Forms', e sua versão final contou com 25 questões fechadas divididas em três seções: identificação dos participantes quanto a gênero, idade e período cursado; caracterização dos participantes quanto ao uso das TDIC; e uso das TDIC no processo de formação inicial docente.

Além das questões objetivas presentes no questionário, os acadêmicos também foram convidados durante um dos encontros presenciais, a participarem no final de um roteiro de entrevista semiestruturada com questões discursivas acerca de suas percepções sobre a utilização das TDIC no âmbito educacional e suas observações durante o Estágio Supervisionado. Dessa forma, os conteúdos produzidos e coletados durante as entrevistas foram processados com auxílio do software IRAMUTEQ, um programa gratuito que permite análise de dados textuais, como a lexicografia, análises de similitude, Classificação Hierárquica Descendente, entre outras.

Todas as questões foram de caráter pessoal e com base nas concepções e percepções dos respondentes, em algumas delas optamos por uma escala do tipo Likert de quatro pontos, para identificar as opiniões dos acadêmicos acerca da importância das tecnologias de maneira geral, sobretudo das TDIC como proposta didático-pedagógica. De acordo com Richardson (2012) [27], entre os diversos instrumentos de coleta de dados, a aplicação de questionários é um dos mais comuns devido a possibilidade de descrever as características e mensurar determinadas variáveis de determinado grupo de participantes.

Após as devidas adequações, o questionário foi disponibilizado para os acadêmicos na plataforma AVA do CESAD, e através do envio do link pelo aplicado WhatsApp. A validação desse instrumento contribuiu para delimitar com clareza a natureza das questões, conforme as dimensões dos conceitos a ser verificados. E para realizar as análises e inferências dos dados produzidos durante a aplicação dos questionários, nos baseamos na perspectiva de Bardin (2016) [28].

Richardson (2012) [27] corrobora com essa discussão ao explanar algumas vantagens da utilização de questionários nas pesquisas, como a possibilidade de se obter informações dos participantes em um tempo relativamente curto, além da facilidade de tabular esses dados para futuras análises quantitativas e qualitativas. Nesse contexto, optamos pelo questionário on-line, considerando as facilidades e comodidades proporcionadas pelas TDIC, na qual Flick (2009) [21] contribui com essa ideia ao argumentar que "muitos dos métodos qualitativos existentes vem sendo transferidos e adaptados às pesquisas que utilizam a internet como ferramenta, como fonte ou como questão de pesquisa" (p. 32).

\section{RESULTADOS E DISCUSSÃO}

Levando em consideração as várias localidades onde os acadêmicos participantes desse estudo residem, bem como suas duplas jornadas de trabalho e estudo, a aplicação de um questionário online permitiu uma coleta e produção de dados de maneira satisfatória, e assim, prosseguir com a realização das demais etapas da pesquisa, algo que certamente demandaria mais tempo com uma aplicação presencial do questionário e inclusive poderia comprometer as atividades destinadas para os encontros presenciais da turma. Esses benefícios eram esperados, pois os recursos tecnológicos, quando aplicados de maneira correta nas pesquisas, correspondem a uma importante estratégia que está cada vez mais acessível para pessoas de modo geral, sem restrições de tempo e espaço, promovendo a comunicação mediante ao uso de e-mail, WhatsApp, chat, entre outras plataformas e ambientes virtuais $[15,26]$.

Os dados obtidos por meio do preenchimento do questionário permitiram identificar algumas características dos licenciandos, e assim, traçar um perfil sociodemográfico desses participantes. A princípio foi constatado um certo desequilíbrio do quantitativo dos respondentes de acordo com o gênero, visto que a amostra dos 22 licenciandos foi constituída por 16 do sexo feminino e 06 do sexo masculino. E no que se refere a faixa etária, a idade média desses participantes correspondeu a 36 anos, com predomínio de $27,2 \%$ para a faixa etária entre 29 e 30 anos, o que na visão de Palfrey e Gasser (2011) [29], caracteriza esses sujeitos, predominantemente, como imigrantes digitais. A distribuição dessa faixa etária está demonstrada na Figura 1, a seguir: 
4

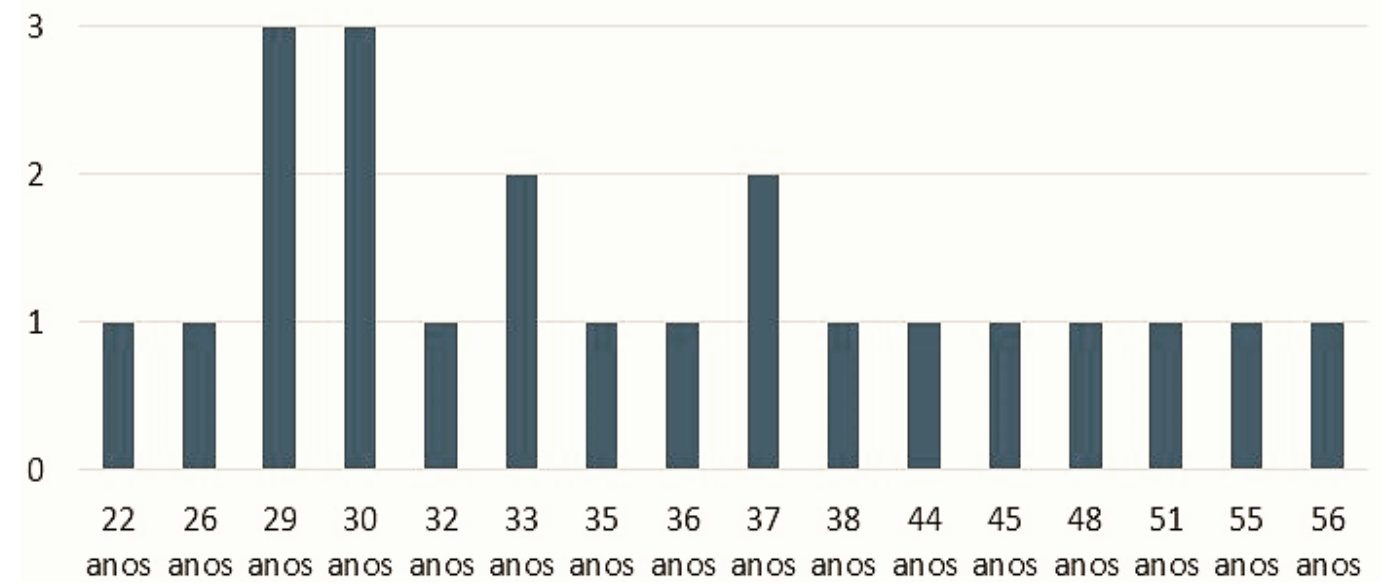

Figura 1: Distribuição das idades dos licenciandos respondentes.

Vale a pena lembrar que essas variações nas idades dos participantes, de 22 a 56 anos, evidenciam uma característica comum dos cursos na modalidade EaD no país, em que boa parte dos participantes é constituída por pessoas adultas, que por algum motivo não conseguiram prosseguir com os estudos enquanto mais jovens [14].

Ampliando essa discussão acerca do ensino à distância, atualmente, o Decreto no 9.057 de 25 de maio de 2017, conceitua a EaD como uma "modalidade educacional na qual a mediação didáticopedagógica nos processos de ensino e aprendizagem ocorre com a utilização de meios e tecnologias de informação e comunicação, com pessoal qualificado, com políticas de acesso, com acompanhamento e avaliação compatíveis" [30]. Essas implicações enfatizam a necessidade de se promover um estudo mais independente, com o desenvolvimento da autonomia dos estudantes nos processos de aprendizagem e organização de estudo conforme suas necessidades e particularidades.

Com relação ao cumprimento dos componentes curriculares, a maioria dos licenciandos se encontrava em fase de conclusão de curso, com 18 deles matriculados no oitavo (e último) período da graduação, e os demais no sétimo e sexto períodos, 03 e 01, respectivamente. Dessa forma, por serem graduandos que se encontravam, em quase sua totalidade, no último período do curso, constata-se que os mesmos já tinham vivenciados, durante seu processo de formação inicial, as disciplinas didáticas e metodológicas, além da realização de estágios supervisionados, bem como práticas de residência pedagógica. Nessa conjuntura, analisar a percepção desses licenciandos sobre o uso das TDIC em seu processo de formação foi de suma importância para entendermos como o uso dessas tecnologias, enquanto recursos didático-pedagógicos, foi enfatizado para os docentes recém-formados e ingressantes no mercado de trabalho.

Ao serem questionados sobre suas opiniões referentes à inserção das TDIC no ambiente escolar, todos os participantes demonstraram concordar sobre a importância que esses dispositivos têm para promover a aprendizagem dos educandos, desde que sejam utilizados adequadamente no ambiente escolar e extraescolar, e por isso, a abordagem desses recursos deve fazer parte da formação inicial e continuada dos professores. No entanto, foi constatado que 06 dos licenciandos, relataram que não foram trabalhadas propostas de utilização dessas tecnologias em sala de aula durante sua formação na universidade, demonstrando assim, a existência de algumas fragilidades na perspectiva de formação inicial desses futuros professores a luz da cultura digital.

Quando questionados ainda sobre quais os fatores que poderiam ter dificultado a abordagem das TDIC no seu curso de licenciatura, a maioria dos participantes citou falta de interesse dos professores da universidade, inclusive de alguns tutores, bem como falta de motivação da turma e carência de recursos didáticos e tecnológicos, como acesso à internet, entre outros. Alguns participantes relataram também a falta de capacitação dos seus professores e tutores em explorar os recursos do AVA, quantidade reduzida de encontros presenciais e a própria dificuldade em 
utilizar as TDIC no cotidiano, como possíveis limitações que dificultaram a implementação e melhor aproveitamento por parte dos discentes, de propostas didáticas envolvendo essas tecnologias digitais em sua formação. Com efeito, essa discussão reafirma alguns resultados encontrados por Santos et al. (2020) [15], num estudo bibliográfico envolvendo relatos de experiências docentes, na qual a "ausência de abordagens tecnológicas, tanto nos cursos de formação de professores em nível das licenciaturas, quanto nos cursos de formação continuada" (p. 23), é uma realidade decorrente de diversos fatores, como a falta de recursos e até mesmo falta de conhecimento ou habilidade para utilizar a tecnologia de maneira aliada e integrada a atividade docente.

Nesse sentido, para verificar como os licenciandos participantes da pesquisa, apesar de cursarem uma graduação na modalidade $\mathrm{EaD}$, avaliavam seu grau de familiaridade e domínio com relação ao uso das TDIC, bem como a frequência com que eles utilizavam essas tecnologias em suas práticas cotidianas, todas as questões submetidas foram de cunho pessoal, e especificamente as da segunda seção do questionário, permitiram conhecer aspectos da cultura digital desses participantes. Alguns desses dados estão apresentados na Tabela 1, a seguir.

Tabela 1: Frequência das respostas quanto ao domínio e utilização das TDIC.

\begin{tabular}{|c|c|c|c|c|}
\hline QUESTÕES & Insuficiente & Pouco & Satisfatório & Avançado \\
\hline \multirow[t]{2}{*}{$\begin{array}{l}\text { Como você avalia seus conhecimentos e } \\
\text { habilidades para lidar com as TDIC no dia a dia? }\end{array}$} & - & $4(18 \%)$ & $14(64 \%)$ & $4(18 \%)$ \\
\hline & $\begin{array}{c}\text { até } \\
1 \mathrm{x} / \mathrm{sem} .\end{array}$ & $\begin{array}{l}\operatorname{de} 2 \text { a } \\
4 x / \text { sem. }\end{array}$ & $\begin{array}{l}\text { de } 4 \text { a } \\
6 x / \text { sem. }\end{array}$ & $\begin{array}{l}\text { todos os } \\
\text { dias }\end{array}$ \\
\hline $\begin{array}{l}\text { Com que frequência você utiliza o computador } \\
\text { ou notebook? }\end{array}$ & $2(9 \%)$ & $7(32 \%)$ & $4(18 \%)$ & $9(41 \%)$ \\
\hline Com que frequência você utiliza a internet? & - & $2(9 \%)$ & $2(9 \%)$ & $18(82 \%)$ \\
\hline $\begin{array}{l}\text { Com que frequência você utiliza o smartphone } \\
\text { ou tablet? }\end{array}$ & $1(4,5 \%)$ & $1(4,5 \%)$ & $1(4,5 \%)$ & $19(87 \%)$ \\
\hline
\end{tabular}

Com base nos dados apresentados na Tabela 1, é possível perceber que 18 dos licenciandos considerando os níveis satisfatório e avançado -, afirmaram possuir elevado nível de conhecimento e habilidades sobre a utilização das TDIC em seu cotidiano, entretanto 04 deles relataram possuir pouco domínio, o que pode ser interpretado como certa dificuldade em manusear essas tecnologias. Infere-se que o fato de alguns serem imigrantes digitais, juntamente com possíveis dificuldades de acesso a essas tecnologias no decorrer de suas vivências profissionais e acadêmicas, tenham contribuído para essa realidade. Quanto à frequência do uso desses dispositivos, a maioria (mais de $80 \%$ ) relatou acessar a internet todos os dias da semana, sendo o smartphone e/ou tablet os dispositivos mais utilizados. Ainda nesse bloco de questões, a maioria dos acadêmicos informou que esse acesso à internet ocorre no ambiente domiciliar, outros referiram acessar a rede na universidade e/ou no local de trabalho, apontando uma interconexão desses participantes com a sociedade digital.

Dentre os 22 licenciandos, apenas 07 se disponibilizaram em participar da entrevista ao término de um dos encontros presenciais, esse baixo quantitativo se justifica devido ao fato da maioria residir em outros municípios e necessitar de transporte público ou de terceiros para retorno às suas casas, e por isso não podiam aguardar por mais tempo além do já esperado. Dessa forma, além das respostas obtidas com a aplicação do questionário, analisamos também as narrativas desses acadêmicos por meio do software IRAMUTEQ, especificamente no que se refere a análise se similitude. 
Convém ressaltar que a análise de similitude, ou de semelhanças, é uma técnica recorrentes nas pesquisas sociais que possibilita identificar e estabelecer conexões entre palavras, classificá-las e relacioná-las num corpus textual [31,32]. Por meio dessa análise foi possível perceber como os licenciandos relacionam suas opiniões acerca do uso das TDIC no âmbito escolar e na sociedade digital como um todo. Na Figura 2, a seguir, apresentamos uma representação gráfica dessa análise produzida no IRAMUTEQ.

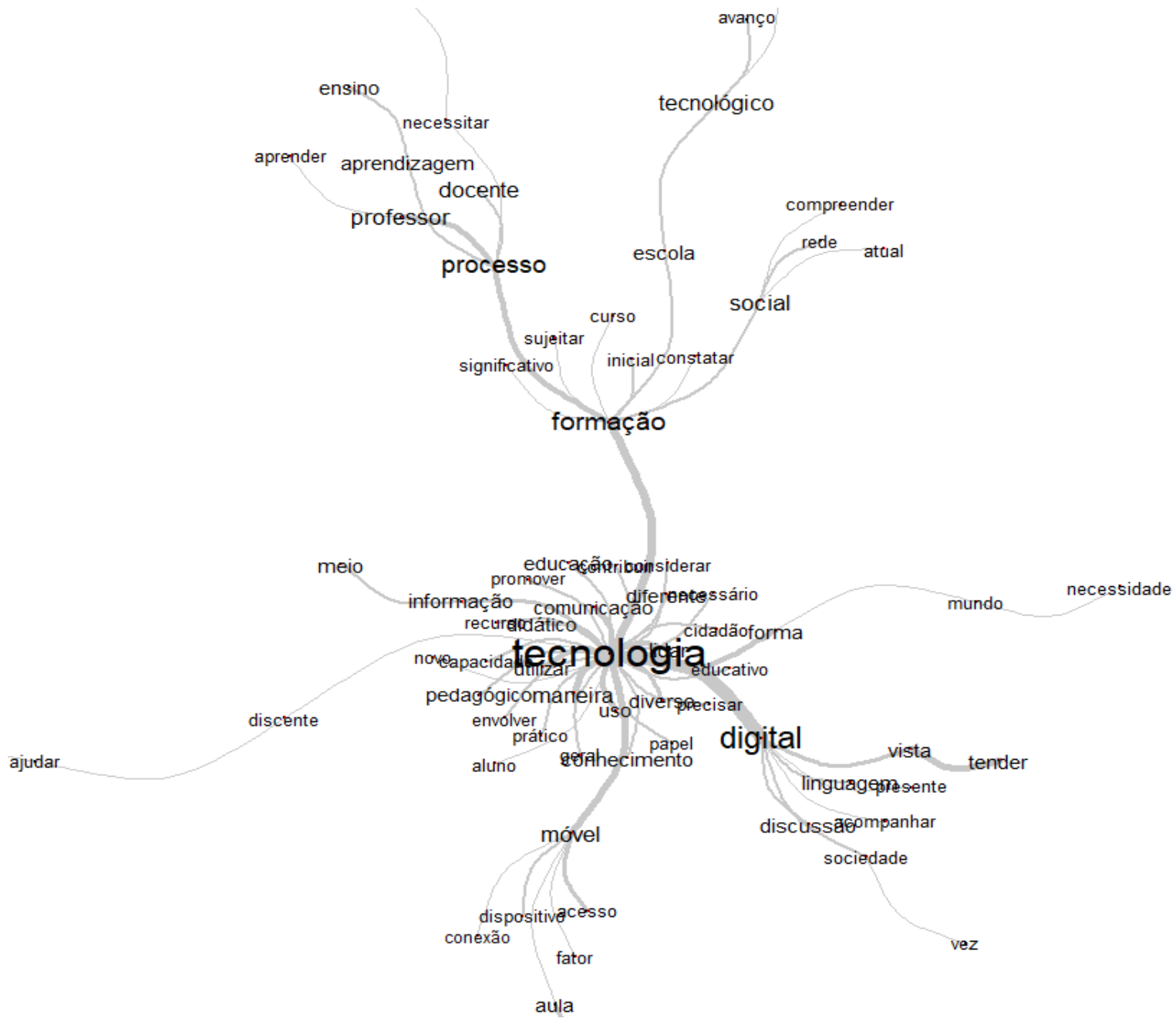

Figura 2: Dendrograma de similitude das narrativas dos participantes acerca das TDIC.

Ao analisar a similitude representada nesse diagrama em formato de árvore de palavras na Figura 2, é possível identificar em sua estrutura, um eixo central e alguns sistemas periféricos das narrativas dos sujeitos acerca do uso das TDIC enquanto estratégias didático-pedagógicas trabalhadas em seu processo de formação, na qual torna-se evidente as possíveis relações que as tecnologias estabelecem com diversas representações sociais, sobretudo com o domínio e interpretação de variadas formas de linguagens, assim como a ênfase no processo de ensinoaprendizagem, o crescente avanço dos sistemas de informação, e com diversas outras classes inerentes ao sistema cada vez mais globalizado. Visando ampliar ainda mais essa discussão, podemos estabelecer uma comparação entre esse dendrograma com uma nuvem de frequência das palavras mencionadas pelos participantes durante a entrevista - também elaborada por meio do IRAMUTEQ -, conforme podemos observar na Figura 3. 


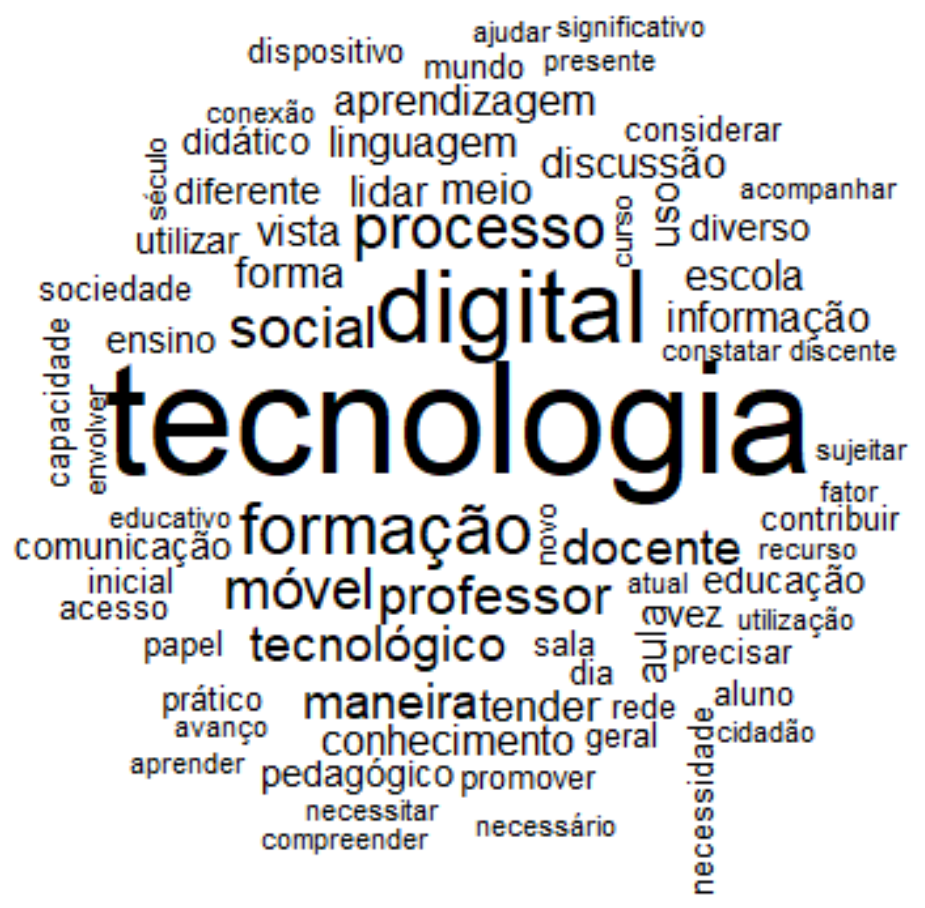

Figura 3: Nuvem de frequência das palavras.

Os diagramas em formato de nuvem representam um agrupamento graficamente organizado das palavras conforme sua frequência [31, 32]. É possível verificar na Figura 2, um destaque para duas grandes ramificações, 'formação' e 'digital' que partem do núcleo central e se entendem por diversos tópicos que foram discutidos neste trabalho, na qual esses e os demais classes de palavras periféricas também estão em destaque na Figura 3, e todas essas representações das narrativas se caracterizam por estar relacionadas em torno do eixo central, o que evidencia uma importante interconexão desses elementos no ciberespaço, na qual, de acordo com Lemos (2015) [6], esse ciberespaço corresponde a um ecossistema complexo e interdepende entre o "macrossistema tecnológico (a rede de máquinas interligadas) e o microssistema social (a dinâmica dos usuários), construindo-se pela disseminação da informação, pelo fluxo de dados e pelas relações sociais aí criadas" (p. 138).

Finalmente, ao serem indagados sobre suas vivências durante a realização dos estágios supervisionados, a maioria informou ter observado que os professores regentes faziam uso das TDIC nas aulas, sendo que a maior frequência relatada dessa prática foi de uma a duas vezes ao mês. E quando questionados sobre quais recursos tecnológicos foram utilizados por esses professores durante o período do estágio, os participantes relataram que se tratava apenas do uso do notebook e do projetor para apresentação de slides ou outras multimídias de imagens, vídeos e sons, o que reforça ainda mais a necessidade de maior apropriação dessas tecnologias também por parte dos professores atuantes na Educação Básica.

\section{CONCLUSÃO}

As discussões e reflexões levantadas neste estudo permitiram analisar como as TDIC, de maneira geral, são trabalhadas e enfatizadas enquanto recursos didático-metodológicos durante o processo de formação inicial docente perante a turma participante. A literatura pesquisada e os dados produzidos por meio do questionário e das entrevistas apontam que as tecnologias em geral, sobretudo os dispositivos móveis digitais, quando utilizados conscientemente e de maneira responsável, podem contribuir fundamentalmente para a formação crítica e cidadã das pessoas, na qual a escola, assumindo seu papel de instituição social responsável pelo desenvolvido intelectual e atitudinal dos alunos, precisa promover o manejo e reflexão crítica quanto ao uso dessas 
tecnologias. Nessa perspectiva, o letramento digital docente necessita estar em conformidade com um trabalho educativo significativo, desde o processo de formação inicial, para garantir aos professores condições necessárias para poderem lidar com as diversas tecnologias, interpretando suas linguagens e criando novas formas de expressão para promover uma aprendizagem mais significativa.

Apesar da cultura digital estar presente em todas as dimensões da dinâmica sociocultural contemporânea, caracterizada por uma série de transformações decorrentes da evolução tecnológica, foi constatado neste estudo, a existência de algumas barreiras que dificultam a inserção ou continuidade de abordagens envolvendo essas tecnologias na turma de $\mathrm{EaD}$ do curso de Licenciatura em Ciências Biológicas pesquisada, pois, alguns acadêmicos relataram que mesmo diante dessas revoluções tecnológicas, as propostas didático-metodológicas envolvendo as TDIC ainda são ausentes ou escassas em sua formação. Portanto, é notório a importância de se enfatizar essa temática durante todo o processo de formação docente, para que os professores possam atuar com competência diante dos diversos meios de propagação e promoção do conhecimento e da aprendizagem e ao mesmo tempo, lidar com as diversas tecnologias e suas formas de expressão e interação em sua atividade docente.

\section{AGRADECIMENTOS}

Agradecemos à Coordenação de Aperfeiçoamento de Pessoal de Nível Superior - Brasil (CAPES) e ao Programa de Pós-Graduação em Educação (PPGED/UFS) pelo incentivo e apoio financeiro essencial para realização dessa pesquisa.

\section{REFERÊNCIAS BIBLIOGRÁFICAS}

1. Lévy P. Cibercultura. 2. ed. Da Costa CI, tradutor. São Paulo (SP): Edições Loyola; 1999. 272 p.

2. Kenski VM. Tecnologias e ensino presencial e a distância. Campinas (SP): Papirus; 2003. 160 p.

3. Teixeira SA. Fazendo pesquisa escolar na Internet [dissertação]. Belo Horizonte (MG): Universidade Federal de Minas Gerais; 2011. 175 p.

4. Marinho SPP, Costa FJ, Carneiro FC, Oliveira PA, Nicolau R. Tecnologias móveis, mídias e redes sociais: cultura de uso de estudantes de licenciatura. Anais dos Workshops do Congresso Brasileiro de Informática na Educação. 2015;834-43, doi: 10.5753/cbie.wcbie.2015.834

5. Silva EGM, Moraes DAF. O uso pedagógico das TDIC no processo de ensino e aprendizagem: caminhos, limites e possibilidades. Ivaiporã (PR): Universidade Estadual de Londrina; 2014. (Governo do Estado do Paraná, Secretaria de Educação, editores. Cadernos PDF; vol I).

6. Lemos A. Cibercultura: tecnologia e vida social na cultura contemporânea. 7. ed. Porto Alegre (RS): Sulina; 2015. $295 \mathrm{p}$.

7. Ferrete AASS, Ferrete RB. Tecnologias móveis no ambiente escolar: desafios e reflexões. Anais dos Workshops do Congresso Brasileiro de Informática na Educação. 2014;360-69, doi: 10.5753/cbie.wcbie.2014.360

8. Ferrete AASS, Ferrete RB. Formação docente: percepções dos professores sobre o uso das tecnologias móveis digitais no processo de ensino e aprendizagem. Anais dos Workshops do Congresso Brasileiro de Informática na Educação. 2017;515-23, doi: 10.5753/cbie.wcbie.2017.515

9. Peci A. RAP | Ações e Estratégias COVID-19. SciELO em Perspectiva [Internet]; 30 mar 2020 [acesso em 03 jun 2020]. Disponível em: https://blog.scielo.org/blog/2020/03/30/rap-acoes-e-estrategias-covid19/\#.YB6f--hKjIU

10. Gewehr D. Tecnologias digitais de informação e comunicação (TDICs) na escola e em ambientes não escolares [dissertação]. Lajeado (RS): Centro Universitário UNIVATES; 2016. 137 p. Disponível em: https://www.univates.br/bdu/bitstream/10737/1576/1/2016DiogenesGewehr.pdf

11. Brasil. Lei de Diretrizes e Bases da Educação Nacional. No 9.394/96. Brasília: Congresso Nacional/MEC; 1997 [acesso em 16 fev 2021]. Disponível em: http://www.planalto.gov.br/ccivil_03/leis/19394.htm

12. Brasil. Base Nacional Comum Curricular [Internet]. Brasília (DF): MEC/Secretaria de Educação Básica, Governo Federal; 2018 [acesso em 07 abr 2020]. Disponível em: http://basenacionalcomum.mec.gov.br/abase/

13. Brasil, Ministério da Educação. Portaria No 343, de 17 de março de 2020. Dispõe sobre a substituição das aulas presenciais por aulas em meios digitais enquanto durar a situação de pandemia do Novo Coronavírus 
- COVID-19. Diário Oficial da União. 18 mar 2020;53(Seção 1):39. Disponível em: http://www.in.gov.br/web/dou/-/portaria-n-343-de-17-de-marco-de-2020-248564376.

14. Alves MMS, Ferrete AASS, Santos WL. As tecnologias móveis digitais da informação e comunicação presentes na formação inicial docente em ciências biológicas. \#Tear: Revista de Educação, Ciência e Tecnologia. 2020;9(2):1-20, doi: 10.35819/tear.v9.n2.a4520

15. Santos WL, Ferrete AASS, Alves MMS. A produção do conhecimento sobre Facebook e educação no portal de periódicos da CAPES: relatos de experiências docentes. Revista Exitus. 2020 Abr;10(1):1-28, doi: $10.24065 / 2237-9460.2020 \mathrm{v} 10 \mathrm{n} 0 \mathrm{ID} 1255$

16. Castells M. A sociedade em rede. v. 1. 2. ed. São Paulo (SP): Paz e Terra; 1999. 455 p.

17. Garcia RPM. Interatividade: uma estratégia de negociação em prol da avaliação na educação a distância. In: Burnham TF, Mattos MLP, organizadores. Tecnologias da informação e educação à distância. 2. ed. Salvador (BA): EDUFBA; 2010. p. 133-153.

18. Mattar J. Tutoria e interação em educação a distância. São Paulo (SP): Cengage Learning; 2012. 240 p.

19. Ferrete AASS, Ferrete RB. As tecnologias móveis digitais nos cursos de licenciatura. Anais dos Workshops do Congresso Brasileiro de Informática na Educação. 2017;584-93, doi: 10.5753/cbie.wcbie.2017.584

20. Creswell JW. Projeto de pesquisa: métodos qualitativo, quantitativo e misto. 3. ed. Porto Alegre (RS): Artmed; 2010. 296 p.

21. Flick U. Introdução à pesquisa qualitativa. Tradução Joice Elias Costa. 3. ed. Porto Alegre (RS): Artmed; 2009. $405 \mathrm{p}$.

22. Rodrigues BM. Interfaces interativas nos processos comunicacionais do curso de química [dissertação]. São Cristovação (SE): Universidade Federal de Sergipe; 2018. 171 p.

23. Brasil, Ministério da Saúde, Conselho Nacional de Saúde. Resolução no 510, de 07 de abril de 2016. Diário Oficial da União. 24 mai 2016;98(Seção 1):44. Disponível em: https://bvsms.saude.gov.br/bvs/saudelegis/cns/2016/res0510_07_04_2016.html

24. Pasquali L. Psicometria. Rev Esc Enferm USP. 2009;43(Esp):992-9.

25. Jesus EMS. Desenvolvimento e validação de conteúdo de um instrumento para avaliação da assistência farmacêutica em hospitais de Sergipe [dissertação]. São Cristóvão (SE): Universidade Federal de Sergipe; 2013. $152 \mathrm{p}$.

26. Alves MMS. Vulnerabilidade às IST/AIDS: desenvolvimento e validação de um instrumento de avaliação inspirado nas questões sociocientíficas [dissertação]. São Cristóvão (SE): Universidade Federal de Sergipe; $2019.217 \mathrm{p}$.

27. Richardson RJ. Pesquisa social: métodos e técnicas. 3. ed. São Paulo (SP): Atlas; 2012. 333 p.

28. Bardin L. Análise de conteúdo. Reto LA, Pinheiro A, tradutores. São Paulo (SP): Edições 70; 2016. 279 p.

29. Palfrey J, Gasser U. Nascidos na Era Digital: entendendo a primeira geração de nativos digitais. Porto Alegre (RS): Artmed; 2011. $352 \mathrm{p}$

30. Brasil. Decreto $\mathrm{n}^{\circ}$ 9.057, de 25 de maio de 2017. Regulamenta o art. 80 da Lei $\mathrm{n}^{\circ} 9.394$, de 20 de dezembro de 1996, que estabelece as diretrizes e bases da educação nacional. Diário Oficial da União. 26 mai 2017;100(Seção 1):3. Disponível em: http://www.planalto.gov.br/ccivil_03/_ato20152018/2017/decreto/d9057.htm.

31. Pontes APM, Oliveira DC, Gomes AMT. Os princípios do Sistema Único de Saúde estudados a partir da análise de similitude. Rev Latino-Am Enfermagem. 2014;22(1):59-65, doi: 10.1590/01041169.2925 .2395

32. Mendes FRP, Zangão MOB, Gemito MLGP, Serra ICC. Representações sociais dos estudantes de enfermagem sobre assistência hospitalar e atenção primária. Rev Bras Enferm. 2016;69(2):343-50, doi: 10.1590/0034-7167.2016690218i 